during the sharp rise and fall of the Glasgow industrial load at the midday dinner hour and other similar occasions. It is satisfactory to learn that after the results of the first twelve months' operation of the first half of the scheme, which includes the two power stations of Tongland and Glenlee, having plant aggregating 57,000 kilowatt, the financial future of the undertaking seems assured.

\section{"Concerning Human Progress"}

Dr. H. S. HARRISON was characteristically stimulating in his presidential address to the Royal Anthropological Institute on June 30, when he spoke "Concerning Human Progress". Unquestionably his choice of a topic was apt to the needs of contemporary thought, which may well look to the anthropologist for guidance on such questions as the direction and mechanism of human development. Dr. Harrison's conclusions, however, gave his hearers little cause for complacency. He showed no little courage in electing neither to attempt a strict definition of progress, nor to lay down canons of discrimination between upward and downward, in the direction of change. In the event, however, when once he had pointed out that the idea of progress is a modern growth, which did not affect human development until the latter part of the nineteenth century, this deliberate omission enabled him, speaking more especially as a technologist, to demonstrate the essential opportunism of cultural development in the past, which has moved continually forward, backward and sideways, without knowledge of what the direction might be, and not infrequently has led to a dead end. Social progress, he went on to point out, has had no better guidance; but as codes of conduct and actual behaviour are the objective revelations of the mind of man, individually or collectively, and both the material and immaterial products of the human mind have trespassed far beyond the biological necessities, the question arises whether the mind of man has been moulded in response. Dr. Harrison, quite rightly, stressed the apparent paradox that, so far as the evidence goes, there is little, if any, difference to be discerned in physical character and brain power between the earliest example of Homo sapiens and the man of to-day. If we look for the directional factor which might have brought about a change in the heart and mind of man, of those forces which have been put forward as active in organic evolution, use-inheritance alone appears to fulfil the requirement, but is ruled out of court, owing to its general repudiation by the biologist. Hence, Dr. Harrison concluded on a note of pessimism, "the mind of man . . . has little sense of direction, and if it may be said to have an ultimate aim, that aim is too obscure for formulation."

\section{The Osborne Reynolds Ridge}

The recent letters in Nature from Prof. W. Schmidt and Prof. H. Stansfield, describing their observations of a capillary wave on the surface of water, are a reminder that important published observations may be forgotten for many years. Prof.
Stansfield now finds that this phenomenon was described by Osborne Reynolds in 1881. Reynolds produced the wave by dropping oil on water, and also observed it in the open air, perhaps when he was fishing, as he says it looks like a line of gut floating on a river, where the water eddies up to the surface in deep pools. About forty years later, there was fresh activity in the study of moving films. In September, 1921, the late Mr. E. Edser quoted Reynolds's paper at a meeting of the Faraday Society, and described experiments showing that the moving film of oil sets in motion a thin layer of water beneath it. Five years before, in Toronto, Prof. J. Satterly had noticed a 'ripple' which moves up a glass tube in advance of the liquid meniscus, when the tube is being filled from below; this and other effects similar to the Reynolds ridge were under investigation there. Five years later, Burdon of Adelaide published a photograph of oil spreading on the surface of water, clearly showing the Reynolds ridge in advance of the visible oil film; and in the same year, 1926, Edser included this photograph and a discussion of the ridge in Appendix IV of his "General Physics for Students". When the rising generation of physicists see the Reynolds ridge, they should recognize it at once as an old friend.

\section{Syria and Crete: Further Discoveries}

Sir Leonard Woolley's further report on his excavations in Syria is a striking justification of the prescience which sought in the area at the mouth of the Orontes evidence for the early relation of the civilizations of Crete and western Asia. The evidence which has been brought to light since the dispatch of his first report (see NATURE of June 13, p. 979) carries the story of the Egean connexions of Syria from c. 900 B.c., the point at which the settlement at Tell Sheikh Yusuf begins, back to the Middle Minoan age of Crete, somewhere between 1700 and 1580 B.c. At Tell Atchana, a mound near the bank of the Orontes, half-way across the Amk plain in the rear of the Amanus mountains, Sir Leonard reports in The Times of June 25, trial excavations in a single trench, which lasted for no more than a fortnight, produced evidence of the existence in the heart of Syria of a city settlement, which was predominantly Cretan in character, and was deserted entirely not later than the twelfth century B.c. At an earlier stage of its history this city had been ravaged by fire and sword, as was shown by the evidence of the large buildings, of which the firescarred remains were uncovered. Here the floors were littered with fragments of pottery, among which Syrian wares were mingled with sherds showing characteristic Minoan motifs, as well as with specimens of the art of, at present, unknown provenance previously reported. The evidence indicates that the destruction of the building took place before the Late Minoan age began. The find of a Minoan bronze sword is balanced by a Mesopotamian bronze axe and chisels and cylinder seals. The link between Crete and the site on the Amk plain has yet to be demonstrated; but a clue is afforded by the ridge- 